\title{
Long Term Exposure to Malaria and Development: Disaggregate Evidence for Contemporaneous Africa
}

\author{
Matteo Cervellati \\ University of Bologna \\ IZA, Bonn \\ CESIfo, Munich
}

\author{
Elena Esposito \\ HEC, Lausanne
}

\author{
Uwe Sunde \\ LMU Munich \\ IZA, Bonn \\ CESIfo, Munich \\ CEPR London
}

October 2016

\begin{abstract}
Malaria afflicts mankind since thousands of years and still imposes serious health impediments and considerable mortality on the affected populations. Empirical investigations of the role of malaria for economic development at the country level deliver mixed findings, however. We study the role of long term Malaria exposure on development today using disaggregate within-country variation for the whole of Africa with $1 \times 1$ degree cells as units of observation. Local development is measured by light density at night. Based on insights from epidemiology, which documents that genetic and acquired immunities reduce Malaria risk for adults in holoendemic areas, the effect is hypothesized to be non-linear, with a peak for intermediate rather than high exposure to the pathogen. The empirical findings support this hypothesis. The results also suggest the existence of a significant moderating effect of genetic immunities measured by the prevalence of the sickle cell trait in the population.
\end{abstract}

JEL-classification: J1, I15 and C13

Keywords: Long Term Exposure to Malaria, Acquired Immunities, Genetic Immunities, Night Lights per Capita, Disaggregated Data Africa.

Contact: Matteo Cervellati m.cervellati@unibo.it, Elena Esposito Elena.Esposito1@unil.ch, Uwe Sunde uwe.sunde@lmu.de

This article has been published in Journal of Demographic Economics [https://doi.org/10.1017/dem.2016.27]. This version is free to view and download for private research and study only. Not for re-distribution, re-sale or use in derivative works. (C) 2017 Universite catholique de Louvain. 


\section{Introduction}

Malaria has affected Africans since at least 10,000 years. Historically a major human killer, the disease still induced 200 million clinical cases worldwide in 2013, causing up to 800,000 malaria-related deaths. $90 \%$ of these have been estimated to occur South of the Sahara in Africa. ${ }^{1}$ Malaria infections not only cause mortality but also morbidity, accounting for ten percent of hospital admissions in Sub Saharan Africa, and involve sizable economic losses. ${ }^{2}$ Surveys from several African countries record illness as the main risk perceived by individuals (followed by shortages of food). ${ }^{3}$

Despite this, available empirical estimates of the effect of malaria for economic development are mixed and the role of the exposure to the pathogen for development is intensely debated. The earlier findings of a sizable negative effect of exposure to malaria on income per capita across countries, see, e.g., Gallup et al. (1999), Gallup and Sachs (2001) and Sachs (2003), have been qualified and questioned subsequently, see Weil (2010, 2011, 2014 and 2016). Recently, the focus has shifted to the analysis of disaggregate data, which provide substantial advantages with respect to identification. The results of the long-term effect of exposure to malaria on pre-colonial African development at the sub-national (ethnic group) level by Depetris-Chauvin and Weil (2016) reveal, however, no sizable and significant effect.

This paper contributes an exploration of the role of long term exposure to malaria for economic development today using disaggregate, grid-cell, data for Sub-Saharan Africa. In general, higher mortality can be a burden for economic development both directly, e.g. through lower labor productivity, and indirectly, by reducing the incentives for long term investments (most notably education and savings) or by reducing the opportunity costs to predation and civil violence. ${ }^{4}$ Mortality also affects population growth and, therefore, population density in the long run. The predicted overall effect on income per capita, or equivalently on disaggregate proxies like night lights per capita, is

\footnotetext{
${ }^{1}$ Malaria has been estimated to have killed half of the humans that ever lived, see Whitfield (2002). See also http://www.who.int/mediacentre/factsheets/fs094/en and http://www.cdc.gov/malaria/about/facts.

${ }^{2}$ Malaria has been estimated to absorb about a quarter of household revenues only for treatments. See, for instance, http://malaria.jhsph.edu/about-malaria/. A single bout of malaria has been estimated to induce an income damage to a sum equivalent to 10-20 working days. See, e.g., Onwujekwe et al. (2000), Deressa et al. (2007), Sicuri et al. (2013) and http://malaria.jhsph.edu/about-malaria/.

${ }^{3}$ Malaria is the most reported illness. See the Parima-Study, Doss et al. (2008) and McPeak et al. (2012).

${ }^{4}$ The role of mortality and pathogen exposure for education is intensely debated, see Cervellati and Sunde (2013). Cervellati, Sunde and Valmori (2016) document that a harsher disease environment across countries increases the likelihood of civil wars, while Cervellati, Esposito, Sunde and Valmori (2016) exploit cell level panel data for SubSaharan Africa and document that temporarily higher malaria risk leads to spikes in civil violence.
} 
therefore generally ambiguous, see Acemoglu and Johnson (2007), Ashraf, Lester and Weil (2008) and Cervellati and Sunde (2011).

This paper adds new empirical evidence on the effect of malaria using a novel identification strategy that is based on epidemiological features of malaria. The first issue in isolating the role of malaria for economic development is identifying the direction of causality. Malaria incidence primarily depends on exogenous geo-climatological conditions. However, it is also affected by economic activity, urbanization, population dynamics and health coverage, as well as by treatment opportunities of infections, among others. Problems of omitted variables and reverse causality have been argued to be particularly serious for an analysis at the level of countries. The use of disaggregate, cell level, data provides substantial advantages in this dimension and also allows exploiting within-country variation. As proxy for local development we use the natural logarithm of night lights per capita, following a recent literature discussed in Section 2. The results document a negative correlation between malaria, measured by a newly released disaggregate data set on clinical incidence of plasmodium falciparum malaria, and night lights per capita. In order to explore the causal effect, we further run intention-totreat regressions using the strength and stability of malaria transmission in a location using the index by Kiszewski et al. (2004). This index provides estimates of "predicted" rather than "actual" malaria exposure using information on locally prevalent malaria vectors and bio-climatological conditions, which are less prone to reverse causality than incidence data. ${ }^{5}$ The results are robust to extensive controls and corroborated when using alternative measures of long term exposure to malaria including endemicity in the African population in 1900.

The second issue, which is very relevant but has been largely overlooked in the empirical literature, is about the empirical specification. The effect of malaria on economic development has been typically explored postulating a linear empirical relationship. The specific features of malaria epidemiology suggest, however, that the effect should be expected to be non-linear. Malaria is the prototypical Mendelian disease. In fact, it is the strongest known selective pressure of the human genome, see Kwiatkowski (2005). In the affected populations, long term exposure to pathogen induced the abnormal diffusion of several types of genetic immunities (mostly, but not only, in terms of blood disorders). Furthermore, in highly endemic areas individuals who survive, potentially repeated, malaria infections at young ages develop acquired immunities, which makes them less susceptible to the pathogen as adults, even to the point of almost eliminating the likelihood of developing severe malaria symptoms and making the disease asymptomatic, see Langhorne et al. (2008). As a result, child mortality tends to increase monotonically with the exposure to the pathogen, whereas the latent

\footnotetext{
${ }^{5}$ The malaria epidemiological background and the estimation strategy is described in further detail in Section 2.
} 
malaria risk for adults is actually higher in areas where malaria transmission stability is comparatively low (less frequent and unstable over time). This feature implies that the effect of malaria on economic activity (which is presumably mostly related to health and mortality of adults rather than children) should be expected to be non-linear (and possibly even non-monotonic). Consistent with these arguments, we find that the effect of Malaria is mostly detrimental for areas with a high latent malaria risk for adults that are characterized by low to intermediate levels of long term exposure to the pathogen. A first exploration of the channel behind the results suggest the important role of genetic immunities (in terms of the spread of the sickle cell trait in the population) as a significant moderating factor in high malaria risk areas.

The paper is organized as follows. Section 2 provides a short discussion of the malaria epidemiology background, presents the data and introduces the empirical strategy. Section 3 presents the results. Section 4 offers some concluding considerations.

\section{Background, Data and Estimation Approach}

This section briefly presents some relevant information concerning the specificities of malaria epidemiology, discusses the data used in the empirical analysis of Section 3 and describes the empirical strategy.

Background: Malaria Epidemiology. Malaria is a vector-transmitted infectious disease caused by the plasmodium parasite. Infections cause severe fevers and frequently lead to death, in particular at child age. Most deaths worldwide are caused by plasmodium falciparum and occur in sub-saharan Africa. The plasmodium parasite cannot be transmitted directly from human to human, transmission occurs exclusively through female anopheles mosquitos, which require blood meals from vertebrate for reproduction. Hence, malaria transmission is closely related to the existence of suitable geographic and climatological conditions favorable for the vector and the reproduction of the parasite. Existing evidence suggests that upon recovery, most infected individuals develop resistance or even protective immunity against the disease, in particular immunity against a lethal infection (Langhorne et. al., 2008). The acquisition of immunity appears to be closely related to the frequent exposure to the pathogen. As a result, protective immunities are most prevalent in highly endemic areas characterized by high and stable exposure to infection (Stanisic et al. 2015). Besides developing acquired immunity, in these areas evolutionary pressure also led to a greater prevalence of genetic immunities, such as the prevalence of the so-called sickle cell trait, an abnormal allele of the hemoglobin beta gene (HbS) 
that implies greater survival chances compared to individuals with normal hemoglobin alleles in the context of plasmodium falciparum infections (Ferreira et al., 2011). As consequence of selective pressure, the prevalence of sickle cell trait is closely related to the exposure to malaria infections.

Data. We use cells of $1 \times 1$ degrees as units of observation. In the following we provide a short description of the main variables of interest and data sources. A more detailed description of the coding of each of the variables and the corresponding data sources is reported in Tables A1 and A2.

Night Light Intensity per Capita. Building on the seminal contribution of Henderson, Storeygard, and Weil (2012), satellite image data on light density at night have recently been used as a proxy for income production at disaggregate level (see, e.g., Chen and Nordhaus, 2011, Pinkovskiy, 2013, Michalopoulos and Papaioannou, 2013, 2014) and Pinkovskiy and Sala-i-Martin, 2014, for recent applications). We follow, in particular, Alesina, Michalopoulos and Papaioannou (2016) and proxy economic development at the disaggregate level building a measure of log "Light Density at Night per Capita" given by Ln(Night Lights/Population), "Log Night lights per Capita", henceforth. ${ }^{6}$ Night light intensity per capita is computed by averaging luminosity observations across pixels that fall within each one degree cell and then dividing by population in that cell. Figure 1 depicts the spatial distribution of night lights and population density. ${ }^{7}$

Exposure to Malaria. Data of projected clinical cases of plasmodium falciparum malaria are from Bhatt et al. (2015) (data are available only for a subset of cells). Since this measure is problematic for reasons discussed below, we use the malaria strength and stability index, henceforth labelled "Malaria Ecology", constructed by Kiszewski et al. (2004) as baseline measure of malaria exposure. The index is a measure of predicted exposure to the pathogen that is built using information on the geo-climatic conditions and the biological characteristics of the dominant mosquito vectors in each location. ${ }^{8}$ To explore the robustness of the findings and the persistence of the effect we use data on

\footnotetext{
${ }^{6}$ African countries are still mostly pre-transitional in terms of the demographic transition, see e.g. Cervellati and Sunde (2015). Differently from developed countries where malthusian mechanisms ceased to be at work, changes in development in Africa can still lead to changes in both economic activity and population density with ambiguous effects on income per capita. See, in particular, Cervellati and Sunde (2011) for a detailed analysis of the role of exposure to pathogens and mortality in countries before and after the demographic transition.

${ }^{7}$ The unconditional correlation between log night lights and log population density is around 0.5.

${ }^{8}$ When constructing this index, Kiszewski et al. (2004) associated to each region a dominant vector of Anopheles mosquitoes (for countries with different dominant vectors, mosquitoes were associated to sub-regions), and used this information together with the respective biting rates of humans of the prevalent vectors and the specific bioclimatological conditions in each location. In our sample the Malaria Ecology Index ranges from 0 (absence of a
} 
Figure 1: Light Density at Night and Population Density

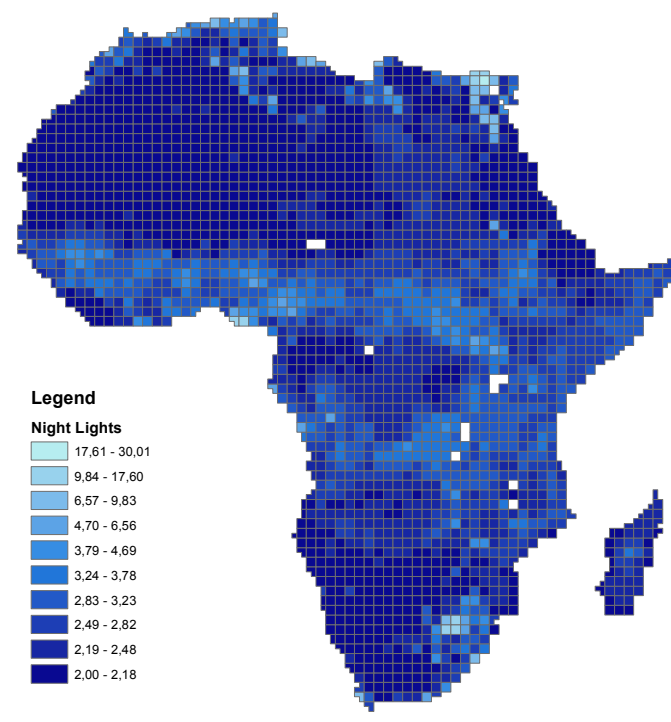

(a) Night Lights Density

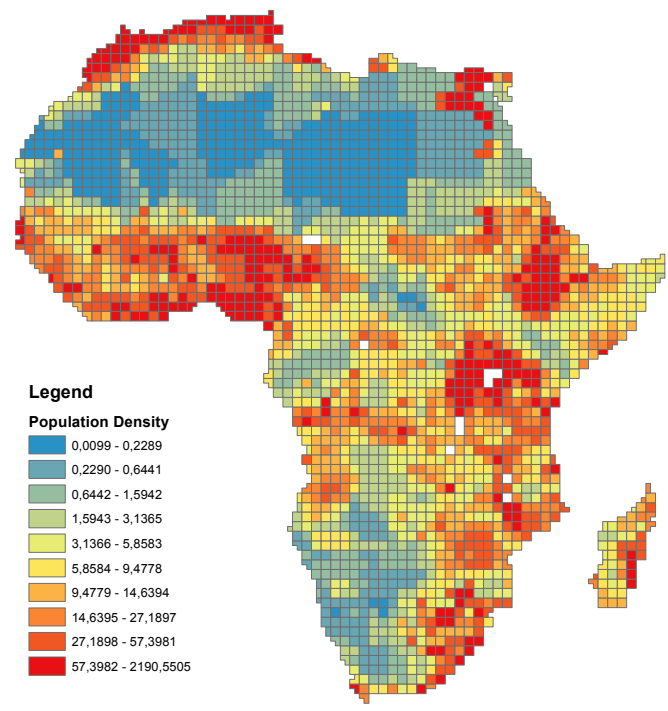

(b) Population Density

Figure 1(a) depicts the spatial distribution of Light Density at Night while Figure 1(b) depicts the distribution of population density. Both figures plot the data over grid cells of $1 \times 1$ degrees in Africa. See Table A1 for data description and sources.

historical malaria endemicity in 1900 constructed by Lysenko and Semashko (1968) and digitalized by Hay et al. (2004). Finally, we use information on the spatial distribution of genetic immunities in terms of the prevalence of the sickle cell trait in the population using data from Piel et al. (2013). Figure 2 depicts the spatial distribution of predicted malaria exposure and of the sickle cell trait.

Table 1 presents the descriptive statistics for the main variables of interest.

Table 1: Descriptive Statistics

\begin{tabular}{lccccc}
\hline \hline & Obs. & Mean & Std. Dev. & Min. & Max \\
\hline Light Density at Night per Capita & 2556 & -1.070 & 1.332 & -5.707 & 1.593 \\
Clinical Incidence of Malaria (Projected) & 1991 & 0.303 & 2.487 & 0 & 108.3 \\
Malaria Ecology Index & 2556 & 8.310 & 9.470 & 0 & 36.4 \\
Malaria Endemicity in 1900 & 2447 & 2.476 & 1.791 & 0 & 5 \\
High Malaria Risk Adults & 2556 & 0.374 & 0.484 & 0 & 1 \\
Genetic Immunities (Sickle Cell Trait) & 2556 & 0.0437 & 0.036 & 0 & 0.167 \\
\hline \hline
\end{tabular}

The description, coding and data sources used to construct each variable are described in details in Table A1.

Covariates. The empirical specification conditions on a large set of cell-specific covariates that could confound the effect of predicted malaria exposure on economic development including proxies for climate (average precipitation and temperatures), geography (mean elevation and average terrain sustainable environment for malaria transmission) to about 36 (high potential for malaria transmission). 
Figure 2: Predicted Malaria Exposure and Genetic Immunities

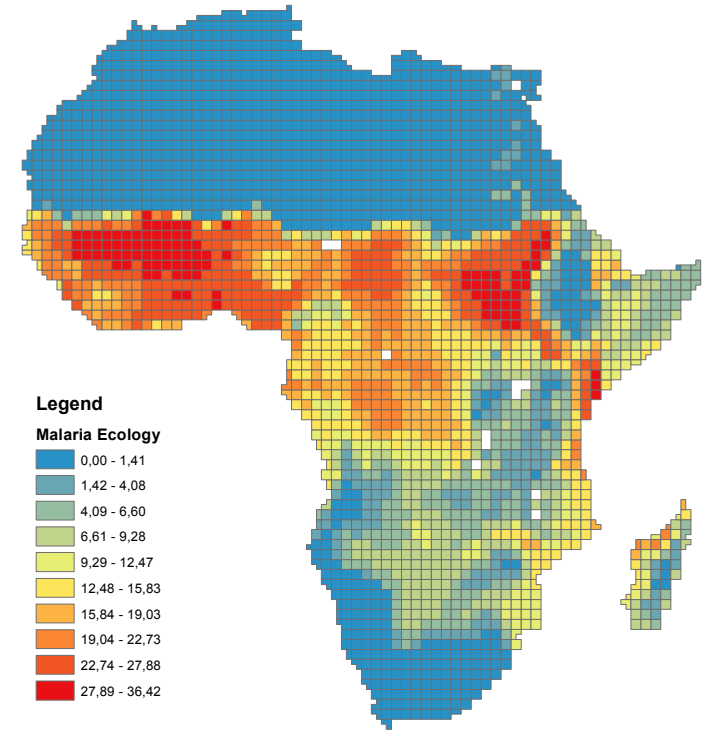

(a) Malaria Stability Index

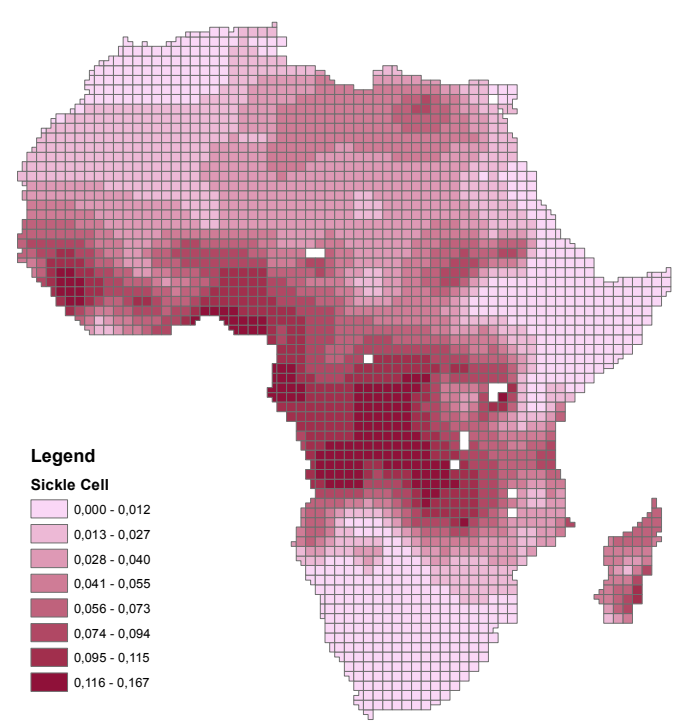

(b) Sickle Cell Traits

Figure 2(a) reports the spatial distribution of the malaria stability index (from Kiszewski et al. (2004)) over grid cells of $1 \times 1$ degrees in Africa. Figure 2(b) reports the respective spatial distribution of the average sickle cell trait in the population. See Table A1 for data description and sources.

ruggedness), natural resources (land suitability for agriculture, the presence of diamond mines and the presence of petrol fields), ethnic inequality as well as a full set of cell area, location and distance controls. The description of the different variables and their data sources is described in details in Table A2.

Estimation Approach. The empirical specification uses cells of $1 \times 1$ degrees for the whole continent of Africa as units of observation. The estimation framework exploits within-country variation in the exposure to the malaria pathogen and economic development by including country fixed effects. This allows controlling for country-specific factors, such as institutions, ethnic composition, as well as historical factors. In addition, the estimation is based on different specifications that subsequently include various sets of control variables to rule out confounding effects. ${ }^{9}$

\footnotetext{
${ }^{9}$ This empirical strategy is similar to the one implemented by Alsan (2015) to isolate the effect of exposure to Trypanosomiasis on African pre-colonial development.
} 


\section{Results}

This section starts by presenting the baseline correlation and the results of intention-to-treat regressions. The analysis then explores the existence of non-linear effects of long term exposure to malaria and the role of interactions between exposure to the pathogen and genetic immunities.

Linear Specification. Table 2 presents the baseline results that exploits variation across cells within a country. Panel A shows the correlation between (projected) clinical incidence of plasmodium falciparum malaria (from Bhatt et al., 2015) and log night lights per capita. Column (1) presents results for the unconditional specification without additional controls. This specification is extended subsequently by including controls for climate, geography and cell area in Column (2), and additionally for location-distances and natural resources in Column (3). Column (4) further adds controls for ethnic diversity with the caveat that, following Cervellati, Chiovelli and Esposito (2016), the number of ethnic groups in a cell is potentially endogenous to the long term exposure to malaria through evolutionary dynamics. The findings throughout all specifications reveal a negative linear relationship between projected incidence of plasmodium falciparum malaria and log night light per capita. These correlations should be taken as purely suggestive, however. The reason is that the projection of malaria incidence is based on survey information about clinical plasmodium falciparum cases that is then extrapolated across time and space. The survey information is likely to be subject to substantial reporting error and might be affected by the occurrence of civil conflict. Moreover, given the spatially and temporally scattered survey data of clinical cases, the extensive use of spatial and temporal interpolation is required to obtain data at the cell-year level (and even using projections only allows for a partial coverage the cells in Africa). In order to obtain the best possible predicted measure of malaria incidence based on limited survey information, the projections make use of a large set of geo-climatological and socio-demographic variables (including population density) that are likely to be directly related to night lights per capita. As consequence, back-projected data on malaria incidence are not suited for the purpose of establishing a causal link between malaria prevalence and development, and the interpretation of these results is therefore potentially problematic.

In order to come up with a more plausible estimate of the causal effect of malaria risk on development, Panel B of Table 2 uses the malaria ecology index from Kiszewski et al. (2004), which provides an indirect measure of malaria incidence based on information about prevalent vectors and bio-climatological characteristics, rather than using projections based on actual clinical incidence from survey data. The use of this measure, which is effectively based on geo-climatological infor- 
mation only, also allows conducting the analysis for the full sample of cells. Moreover, the use of a measure of malaria risk based on exogenous factors, rather than on projections of the actual malaria incidence, limits problems of reverse causality and allows to improve in terms of measurement error, which is a very serious problem for measures of disease incidence in Sub-Saharan Africa. The results confirm the patterns of Panel A. ${ }^{10}$ In particular, the estimates display systematically and significantly negative effect of malaria prevalence on development in terms of log night lights per capita. Incidentally, the effect associated with the coefficient estimates in Panel B is larger in magnitude than in Panel A, which might point to issues of attenuation bias or potential endogeneity in Panel A. ${ }^{11}$

Non-Linear Specifications. In view of the malaria epidemiology literature, the long term exposure to malaria should be expected to influence development, measured by ln night light per capita, in a non-linear way. As discussed in Section 1, the reason is that malaria exposure affects differentially economic activity and population density. Specifically, one would expect malaria to be more detrimental for income per capita for intermediate exposure to the pathogen, which implies a population that is highly susceptible to malaria infections, which are only occurring rather infrequently.

As a first exploration of this issue, Table 3 goes beyond the linear specification and presents results obtained with a non-linear (quadratic) specification. Panel A replicates the analysis with a specification that includes malaria ecology as linear and squared term. Consistent with the hypothesis, the findings reject the null hypothesis of a linear relationship and document the existence of a U-shape relationship between malaria exposure and log night lights per capita. In fact, the effect of malaria appears to be most detrimental for cells with intermediate strength and stability of malaria transmission (i.e., an index of around 18 to 20 on a scale from 0 to 36 ). ${ }^{12}$ As robustness, and to

\footnotetext{
${ }^{10}$ The unconditional correlation between the projected incidence of malaria and the malaria ecology index is 0.63 . The results for the intention-to-treat regressions are also very similar when restricting attention to the subset of cells for which data on estimated incidence are available.

${ }^{11}$ Note that projected Clinical Incidence and Malaria Ecology are not standardized variables, which prevents a direct comparison of the coefficient estimates. Using the estimates, the effect of an increase of one standard deviation in malaria exposure measured by the malaria ecology index is about six times higher than an increase of one standard deviation in the projected malaria incidence. Apart from attenuation bias due to measurement error, this might be due to endogeneity, for instance in light of a plausible positive correlation between development and health or health facilities, which is at the same time negatively related to projected clinical incidence.

${ }^{12}$ This result is consistent with the malaria epidemiology literature and with the findings by Cervellati, Esposito, Sunde and Valmori (2016) on the effect of increases in malaria risk for civil violence. These results can also help rationalizing the evidence by Henderson et al. (2011) of a heterogenous effect of light on income for regions with
} 
Table 2: Linear Specification

\begin{tabular}{lcccc}
\hline \hline Dependent Variable & \multicolumn{4}{c}{ Log Light Density at Night per Capita - Cell Level } \\
\hline & \multicolumn{4}{c}{ Panel A: Clinical Incidence Malaria Falciparum } \\
\cline { 2 - 5 } & $(1)$ & $(2)$ & $(3)$ & $(4)$ \\
\hline Clinical Incidence of Malaria & $-0.025^{* * *}$ & $-0.022^{* * *}$ & $-0.015^{* * *}$ & $-0.015^{* * *}$ \\
(Projected) & $(0.008)$ & $(0.006)$ & $(0.005)$ & $(0.005)$ \\
\hline Observations & 1,991 & 1,991 & 1,991 & 1,991 \\
R-squared & 0.467 & 0.572 & 0.690 & 0.697 \\
\hline & \multicolumn{4}{c}{ Panel B: Malaria Ecology (Intention to Treat) } \\
\cline { 2 - 5 } & $(1)$ & $(2)$ & $(3)$ & $(4)$ \\
Malaria Ecology & $-0.039^{* * *}$ & $-0.045^{* * *}$ & $-0.027^{* *}$ & $-0.024^{* *}$ \\
& $(0.014)$ & $(0.008)$ & $(0.010)$ & $(0.011)$ \\
\hline Observations & 2,556 & 2,556 & 2,556 & 2,556 \\
R-squared & 0.485 & 0.607 & 0.697 & 0.700 \\
\hline Controls (Both Panels)): & \multicolumn{4}{c}{} \\
\hline Climate & No & Yes & Yes & Yes \\
Geography & No & Yes & Yes & Yes \\
Cell Area & No & Yes & Yes & Yes \\
Location-Distances & No & No & Yes & Yes \\
Natural Resources & No & No & Yes & Yes \\
Ethnic Diversity & No & No & No & Yes \\
\hline Country FE & Yes & Yes & Yes & Yes \\
\hline \hline
\end{tabular}

The unit of observation is a $1 \times 1$ degree cell. The dependent variable is the intensity of log night lights per capita. See text for details. Panel A: "Clinical Incidence of Malaria (Projected)" is a projection of clinical incidence of Plasmodium falciparum malaria (per 1000) obtained by interpolating across space and over time available malaria prevalence data retrieved from surveys using a a large number of dynamic environmental and socio-demographic covariates to avoid missing observations. Data are from Bhatt et al. (2015). Panel B: Malaria Ecology is the index of malaria transmission strength and stability by Kiszewski et al. (2004). The "Climate" controls include average precipitation and average temperature. The "Geography" include, mean elevation, average terrain ruggedness. The "Cell Area" controls for the total cell area and the total area of the cell occupied by water. The "Location and Distances" controls include absolute latitude, the natural logarithm of the distance to the country capital, to the coast, to the country border, to the closest river and to Addis Ababa. The "natural resources" controls include the average land suitability for agriculture, the presence of diamond mines and the presence of petrol fields. The "Ethnic-Diversity" controls for the number of ethnic groups in the cell (GREG Database). See Table A1 for description of each variable and the sources, and Table 1 for descriptives. OLS estimates. Robust standard errors in parentheses. ***, **, * indicate significance at 1-, 5-, and 10-\% level, respectively.

explore the persistence of the effect, Panel B replicates the analysis using information on Malaria Endemicity in $1900 .{ }^{13}$ The findings confirm the non-linear, U-shaped pattern of malaria exposure on

different malaria prevalence. In fact, they find the highest effect for the intermediate quartile (with malaria prevalence between 9.27 and 18.61).

${ }^{13}$ The corresponding unconditional correlation between the malaria ecology index and estimates of malaria endemic-

ity in 1900 is 0.69 . 
economic development in terms of light intensity. ${ }^{14}$

Table 3: Non-Linear Effects

\begin{tabular}{|c|c|c|c|c|}
\hline \multirow[t]{3}{*}{ Dependent Variable } & \multicolumn{4}{|c|}{ Log Light Density at Night per Capita - Cell Level } \\
\hline & \multicolumn{4}{|c|}{ Panel A: Malaria Ecology } \\
\hline & (1) & $(2)$ & $(3)$ & (4) \\
\hline Malaria Ecology & $\begin{array}{l}-0.034 \\
(0.046)\end{array}$ & $\begin{array}{c}-0.088^{* * *} \\
(0.024)\end{array}$ & $\begin{array}{c}-0.077^{* * *} \\
(0.022)\end{array}$ & $\begin{array}{c}-0.071^{* * *} \\
(0.023)\end{array}$ \\
\hline Malaria Ecology Squared & $\begin{array}{l}-0.000 \\
(0.001)\end{array}$ & $\begin{array}{l}0.002^{*} \\
(0.001)\end{array}$ & $\begin{array}{c}0.002^{* *} \\
(0.001)\end{array}$ & $\begin{array}{c}0.002^{* *} \\
(0.001)\end{array}$ \\
\hline Observations & 2,556 & 2,556 & 2,556 & 2,556 \\
\hline \multirow[t]{3}{*}{ R-squared } & 0.485 & 0.610 & 0.701 & 0.704 \\
\hline & \multicolumn{4}{|c|}{ Panel B: Malaria Endemicity circa 1900} \\
\hline & (1) & $(2)$ & $(3)$ & (4) \\
\hline Malaria Endemicity 1900 & $\begin{array}{c}-0.767^{* * *} \\
(0.135)\end{array}$ & $\begin{array}{c}-0.730^{* * *} \\
(0.110)\end{array}$ & $\begin{array}{c}-0.455^{* * *} \\
(0.083)\end{array}$ & $\begin{array}{c}-0.437^{* * *} \\
(0.084)\end{array}$ \\
\hline Malaria Endemicity 1900 Squared & $\begin{array}{c}0.086^{* *} \\
(0.034)\end{array}$ & $\begin{array}{c}0.087^{* * *} \\
(0.029)\end{array}$ & $\begin{array}{c}0.048^{* *} \\
(0.020)\end{array}$ & $\begin{array}{c}0.047^{* *} \\
(0.019)\end{array}$ \\
\hline Observations & 2,447 & 2,447 & 2,447 & 2,447 \\
\hline R-squared & 0.568 & 0.649 & 0.720 & 0.722 \\
\hline \multicolumn{5}{|l|}{ Controls (Both Panels) } \\
\hline Climate & No & Yes & Yes & Yes \\
\hline Geography & No & Yes & Yes & Yes \\
\hline Cell Area & No & Yes & Yes & Yes \\
\hline Location-Distances & No & No & Yes & Yes \\
\hline Natural Resources & No & No & Yes & Yes \\
\hline Ethnic Diversity & No & No & No & Yes \\
\hline Country FE & Yes & Yes & Yes & Yes \\
\hline
\end{tabular}

The unit of observation is a 1 x 1 degree cell. The dependent variable is the intensity of log night lights per capita. See text for details. Panel A: "Malaria Ecology" is the index of malaria strength and stability by Kiszewski et al. (2004). Panel B: "Malaria Endemicity in 1900" is the index of average historical malaria endemicity by Lysenko and Semashko (1968) and digitalized by Hay et al. (2004). See the text and the caption of Table 2 for description of the variables included in each category of controls and Table A1 for a description of each variable and their sources, and Table 1 for descriptives. OLS estimates. Robust standard errors in parentheses. $* * *, * *, *$ indicate significance at $1-, 5-$, and $10-\%$ level, respectively.

High Malaria Risk for Adults and Interactions with Genetic Immunities. We end the analysis by exploring the robustness of the findings as well as the potential role of immunities in moderating the detrimental effects of malaria. As a first step, which also reflects the previous findings of a non-linear effect of malaria exposure on development, we construct a binary measure of malaria risk. This measure takes value one for low and intermediate levels of the malaria ecology index, consistent with infrequent exposure to malaria infections and thus a relatively high susceptibility of

\footnotetext{
${ }^{14}$ The minimum is at an endemicity index of around or slightly above 4 .
} 
the population, as compared to cells with high malaria transmission stability and correspondingly frequent infections that are likely to lead to acquired immunity of large parts of the population. Hence, the measure effectively picks up an intermediate range of the malaria ecology index in a binary way, since a value of 1 corresponds to greater effective malaria exposure as consequence of the lack of acquired immunity.

As a first step, we estimate the effect of this binary risk measure on economic performance in terms of log night lights per capita. This effectively provides an additional robustness check of the non-linear effect of malaria exposure by comparing high risk cells to low risk cells. The results reported in Table 4 Panel A document a significantly negative effect of high malaria risk and thereby confirm the earlier findings of a non-linear effect of malaria exposure on development. In particular, the effect of malaria appears to be particularly negative in cells that face a higher latent malaria risk for adults in view of the low levels of immunities in the population as indicated by the epidemiological literature.

As a second step, we extend this analysis by explicitly accounting for the prevalence of genetic immunity in terms of the sickle cell trait in the population, which provides affected individuals with some immunity to malaria parasitization of red blood cells. The prevalence of genetic immunities in the population is informative both on the extent of past malaria exposure and on the existence of genetic immunities to malaria today. Moreover, to the extent that sickle cell prevalence picks up genetic factors, the high malaria risk variable is more likely to reflect (the lack of) acquired immunity. Table 4 Panel B presents the results from this extended empirical specification that explicitly accounts for high malaria risk and the prevalence of the sickle cell trait in the population. The results suggest that both effective malaria risk (reflected in the lack of acquired immunities) and the long term exposure in the past (reflected by the prevalence of genetic immunities) have a negative effect on development in terms of log night lights per capita.

As a last step, we explore the interaction of these two dimensions, extending the contrast between low and high risk areas by the presence of different levels of genetic immunities in terms of sickle cell prevalence. ${ }^{15}$ Finally, the results in Panel $\mathrm{C}$ of Table 4 document the existence of an attenuating effect of the prevalence of genetic immunity in terms of the sickle cell trait, even within high malaria risk areas (as reflected in the positive coefficient for the interaction term). The effect of a high latent malaria risk (i.e., the lack of acquired immunity in the presence of a risk of infection) today

\footnotetext{
${ }^{15} \mathrm{~A}$ similar analysis with a less straightforward interpretation could be conducted with the non-linear specifications. We view the present analysis with a binary indicator of malaria risk as more useful and transparent since there is no reason to believe that the interaction effect is necessarily linear.
} 
Table 4: High Malaria Risk for Adults and Genetic Immunities (Sickle Cells)

\begin{tabular}{lcccc}
\hline \hline Dependent Variable & \multicolumn{4}{c}{ Log Light Density at Night per Capita - Cell Level } \\
\hline & \multicolumn{4}{c}{ Panel A: High Malaria Risk (HMR) Areas } \\
\cline { 2 - 5 } & $(1)$ & $(2)$ & $(3)$ & $(4)$ \\
\hline High Malaria Risk Adults & $-0.847^{* * *}$ & $-0.684^{* * *}$ & $-0.475^{* * *}$ & $-0.474^{* * *}$ \\
& $(0.295)$ & $(0.182)$ & $(0.149)$ & $(0.150)$ \\
\hline Observations & 2,556 & 2,556 & 2,556 & 2,556 \\
R-squared & 0.492 & 0.603 & 0.700 & 0.705 \\
\hline
\end{tabular}

Panel B: HMR and Genetic Immunities

\begin{tabular}{lcccc}
\cline { 2 - 5 } & $(1)$ & $(2)$ & $(3)$ & $(4)$ \\
\hline High Malaria Risk Adults & $-0.872^{* * *}$ & $-0.688^{* * *}$ & $-0.477^{* * *}$ & $-0.478^{* * *}$ \\
Genetic Immunities & $(0.299)$ & $(0.184)$ & $(0.149)$ & $(0.151)$ \\
& $-8.246^{* *}$ & -2.718 & -0.830 & -1.879 \\
& $(3.502)$ & $(2.533)$ & $(2.459)$ & $(2.445)$ \\
\hline Observations & 2,556 & 2,556 & 2,556 & 2,556 \\
R-squared & 0.504 & 0.604 & 0.700 & 0.706 \\
\hline
\end{tabular}

\begin{tabular}{|c|c|c|c|c|}
\hline & \multicolumn{4}{|c|}{ Panel C: Interactions with Genetic Immunities } \\
\hline & (1) & (2) & (3) & (4) \\
\hline High Malaria Risk Adults & $\begin{array}{c}-1.401^{* * *} \\
(0.391)\end{array}$ & $\begin{array}{c}-1.016^{* * *} \\
(0.229)\end{array}$ & $\begin{array}{c}-0.679 * * * \\
(0.183)\end{array}$ & $\begin{array}{c}-0.673^{* * *} \\
(0.186)\end{array}$ \\
\hline Genetic Immunities & $\begin{array}{c}-14.352^{* * *} \\
(3.979)\end{array}$ & $\begin{array}{c}-7.099 * * \\
(3.236)\end{array}$ & $\begin{array}{l}-3.662 \\
(3.255)\end{array}$ & $\begin{array}{l}-4.595 \\
(3.234)\end{array}$ \\
\hline High Malaria Risk $\times$ Genetic Immunities & $\begin{array}{c}11.274^{* * *} \\
(3.637)\end{array}$ & $\begin{array}{c}7.109^{* * * *} \\
(2.512)\end{array}$ & $\begin{array}{l}4.330^{*} \\
(2.317)\end{array}$ & $\begin{array}{l}4.175^{*} \\
(2.290)\end{array}$ \\
\hline Observations & 2,556 & 2,556 & 2,556 & 2,556 \\
\hline R-squared & 0.519 & 0.610 & 0.702 & 0.708 \\
\hline \multicolumn{5}{|l|}{ Controls (All Panels) } \\
\hline Climate & No & Yes & Yes & Yes \\
\hline Geography & No & Yes & Yes & Yes \\
\hline Cell Area & No & Yes & Yes & Yes \\
\hline Location-Distances & No & No & Yes & Yes \\
\hline Natural Resources & No & No & Yes & Yes \\
\hline Ethnic Diversity & No & No & No & Yes \\
\hline Country FE & Yes & Yes & Yes & Yes \\
\hline
\end{tabular}

The unit of observation is a $1 \times 1$ degree cell. The dependent variable is the intensity of log night lights per capita. See text for details. "High Malaria Risk" is a binary indicator for low to intermediate malaria exposure taking value 1 for cells with an average malaria transmission stability index (from Kiszewski et al. (2004)) larger than 0 and lower than 15. Genetic Immunities is the index of Sickle Cell Trait Prevalence (in percentage over the population) by Piel et. al. (2013). See the text and the caption of Table 2 for description of the variables included in each category of controls and Table A1 for a description of each variable and their sources, and Table 1 for descriptives. OLS estimates. Robust standard errors in parentheses. ${ }^{* * *},{ }^{* *},{ }^{*}$ indicate significance at 1-, 5-, and 10-\% level, respectively. 
is reduced by the existence of genetic immunities in the population, which moderates (but not fully eliminates) the negative effect of malaria risk on economic development. However, the total effect remains negative.

Magnitude of the Effects. The interpretation of the magnitude of the economic effect of longterm exposure to malaria requires evaluating the non-linear effect on light density and providing a quantitative mapping between night light intensity and income.

Taking at face value the coefficient estimated in the linear regression of malaria ecology on night lights per capita in Panel B of Table 2, an increase in the malaria ecology index by 1 is associated with reduction in per capita luminosity between 2.4 and 4.5 percent. The results in Table 3 show that the relationship between malaria and night lights is non-linear and U-shaped, however, with a minimum for index values of around 18 to 20. This minimum represents the malaria ecology index for which light density is lowest, i.e., for which the effect is most detrimental. Since the effect varies with the malaria ecology index, a quantitative assessment appears more straightforward in the context of the non-linear estimates obtained with a binary measure of high malaria risk as in Panel A of Table 3. Everything else equal, a high risk to malaria exposure reduces light density by 0.475 log points in the most extensive specifications.

A small but rapidly growing literature addresses the question about the link between measures of night light intensity and economic activity. This literature provides different parametric estimates of the elasticity of several measures of economic activities with respect to several measures of night light intensity. By exploiting within-country variability over time, Henderson, Storeygard, and Weil (2012) provide estimates of elasticities of approximately 0.3 for growth rates and long differences. ${ }^{16}$ The correct mapping from night lights to GDP is far from trivial, however. Furthermore, the interpretation of our findings in terms of GDP per capita is subject to some specific caveats. First, no estimate of the elasticity between light and income within countries is available specifically for Africa. Following on the insights by Bickenbach et al. (2016) the elasticity for Africa might differ from the world average elasticity. Using within country variation across regions with data from Brazil, India, the United States, and Western Europe they obtain significantly different estimates across regions with a lower bound in the range of $0.10 .{ }^{17}$ Second, in light of the nature of the analysis, linking

\footnotetext{
${ }^{16}$ Henderson et al. (2012) use data for 170 countries over the period 1992/93 and 2005/06 on a global scale (and not only for Africa). Estimates reported by Chen and Nordhaus (2011) are somewhat larger in magnitude, in the order of 0.8, but apply a slightly different methodology to account for differences in data quality.

${ }^{17}$ The cross validation exercise by Michalopoulos and Papaioannou (2013b) for Africa suggest a correlation between measures of night light luminosity and wealth (from survey data) in the order of 0.7. To our knowledge, no specific
} 
data of long-term malaria exposure to long-term development, we look at levels of night light density (across regions and within countries) and not growth rates as in the majority of these studies. ${ }^{18}$ Finally, we look at night light per capita (rather than per area) since, as discussed above, the effect of malaria exposure in the long run should be expected to matter for both economic activity and population density.

Some of the available elasticity estimates in the literature discussed above are derived from empirical specifications that are conceptually equivalent to our estimates in levels with country fixed effects. In particular, Henderson et al. (2011) estimate regressions in long differences that link changes in night light per area to changes in GDP. Keeping in mind the previously discussed caveats regarding comparability, heterogeneity and stability of the elasticity, and under the assumption that population levels are sufficiently stable over the observation period, these estimates can be used to get a sense of the bounds of the magnitude of the effect of malaria on income. Considering an elasticity between the two (lower and upper) bounds of 0.10 and 0.30 (as estimated by Bickenbach et al., 2016, and Henderson et. al., 2011), respectively) would imply an effect of the exposure to a high latent malaria risk on GDP per capita within countries in Africa in the range of -5 to -15 percent. ${ }^{19}$

\section{Concluding Remarks}

This paper has explored the role of long term exposure to malaria for African development today using grid cell level data for the whole continent. The results document the existence of a U-shape effect of long term exposure to malaria and disaggregate data of economic development measured by log night lights density per capita. The documented empirical patterns are robust to a set of unreported checks. ${ }^{20}$ The documented patterns are consistent with evidence in malaria epidemiology on the emergence of genetic and acquired immunities that make the latent malaria risk for adults highest for intermediate levels of exposure to the pathogen. The results also suggest a relevant moderating role of genetic immunities. The analysis does not allow to unfold the mechanisms behind the documented regularity, however. Investigations of the channels appear a fruitful direction for estimates are available for the relationship between night light luminosity and economic activity within countries for Africa, however.

${ }^{18}$ Some recent works dispute the use of data on night light luminosity as measures of income per capita growth and suggest a more robust relationships for the respective levels, see e.g. Addison and Stewart (2015).

${ }^{19}$ This magnitude refers to the point estimate of -0.475 as in Columns (3) and (4) of Panel A of Table 3.

${ }^{20}$ In particular they are not driven by outliers in terms of extreme values of population density. The findings are qualitatively and quantitatively very similar when excluding cells with particularly low population density (like arid or desert areas) or very highly populated areas (like highly urbanized clusters) or both. 
future research.

\section{References}

Acemoglu, D., And S. Johnson (2007): "Disease and Development: The Effect of Life Expectancy on Economic Growth," Journal of Political Economy, 115(6), 925-985.

Addison, D., And B. Stewart (2015): "Nighttime Lights Revisited: The Use of Nighttime Lights Data as a Proxy for Economic Variables," Policy Research Working Paper, World Bank, 7496.

Alesina, A., S. Michalopoulos, and E. Papaioannou (2016): "Ethnic Inequality," Journal of Political Economy, forthcoming, 124(2), 428-488.

Alsan, M. (2015): "The Effect of the TseTse Fly on African Development," American Economic Review, 105(1), 382-410.

Ashraf, Q. H., A. Lester, And D. N. Weil (2008): "When Does Improving Health Raise GDP?," mimeo, Brown University.

BhAtт, S., AND OTHERs. (2015): "The effect of malaria control on Plasmodium falciparum in Africa between 2000 and 2015," Nature, 526, 207-211.

Bickenbach, F., E. Bode, P. Nunnenkamp, And M. Söder (2016): "Night lights and regional GDP," Review of World Economics, 152(2), 425-447.

Cervellati, M., G. Chiovelli, and E. Esposito (2016): "Bite and Divide: Ancestral Exposure to Malaria and the Emergence and Persistence of Ethnic Diversity," Mimeo, University of Bologna.

Cervellati, M., E. Esposito, U. Sunde, and S. Valmori (2016): "Malaria Risk and Civil Violence," CEPR Discussion Paper.

Cervellati, M., and U. Sunde (2011): "Life Expectancy and Economic Growth: The Role of the Demographic Transition," Journal of Economic Growth, 16, 99-133.

(2013): "Life Expectancy, Schooling, and Lifetime Labor Supply: Theory and Evidence Revisited," Econometrica, 81(5), 2055-2086.

(2015): "The Economic and Demographic Transition, Mortality, and Comparative Development," American Economic Journal: Macroeconomics, 7(3), 189-225.

Cervellati, M., U. Sunde, and S. Valmori (2016): "Pathogens, Weather Shocks and Civil Conflicts," Economic Journal, forthcoming.

Chen, X., And W. D. Nordhaus (2011): "Using Luminosity Data as a Proxy for Economic Statistics," Proceeedings of the National Academy of Sciences, 108(21), 8589-8594.

Depetris-Chauvin, E., And D. N. Weil (2016): "Malaria and Early African Development: Evidence from the Sickle Cell Trait," Economic Journal, forthcoming.

Deressa, W., D. Hailemariam, and A. Ali (2007): "Economic costs of epidemic malaria to households in rural Ethiopia," Tropical Medicine and International Health, 12(10), 1148-1156.

Doss, C., J. McPeak, and C. B. Barrett (2008): "Interpersonal, Intertemporal and Spatial Variation in Risk Perceptions: Evidence from East Africa," World Development, 36(8), 1453-1468. 
Ferreira, A., I. Marguti, I. Bechmann, V. Jeney, A. Chora, N. R. Palha, S. Rebelo, A. Henri, Y. Beuzard, and M. P. Soares (2011): "Sickle Hemoglobin Confers Tolerance to Plasmodium Infection," Cell, 145(3), 398-409.

Gallup, J. L., And J. D. SAchs (2001): "The Economic Burden of Malaria," American Journal of Tropical Medicine and Hygiene, 64(1), 85-96.

Gallup, J. L., J. D. Sachs, and A. D. Mellinger (1999): "Geography and Economic Development," International Regional Science Review, 22(2), 179-232.

Gilmore, E., N. P. Gleditsch, P. Lujala, and J. K. Rod (2005): "Conflict Diamonds: A New Dataset," Conflict Management and Peace Science, 22(3), 257-292.

Hay, S. I., C. A. Guerra, N. A. M. Tatem, Andy J. And, and R. W. Snow (2004): "The global distribution and population at risk of malaria: past, present and future," Lancet Infectious Diseases, 4(6), 327-336.

Henderson, J. V., A. Storeygard, and D. N. Weil (2012): "Measuring Economic Growth from Outer Space," American Economic Review, 102(2), 994-1028.

John, W. (2002): "Portrait of a serial killer," Nature, 3 October 2002.

Kiszewski, A., A. Mellinger, A. Spielman, P. Malaney, S. E. Sachs, and J. Sachs (2004): "A global index representing the stability of malaria transmission," American Journal of Tropical Medicine and Hygiene, 70(5), 486-498.

Kwiatkowski, D. P. (2005): "How malaria has affected the human genome and what human genetics can teach us about malaria," The American Journal of Human Genetics, 77(2), 171-192.

Langhorne, J., F. M. Ndungu, A.-M. SponaAs, and K. Marsh (2008): "Immunity to malaria: more questions than answers," Nature immunology, 9(7), 725-732.

Lujala, P., J. K. Rod, and N. Thieme (2007): "Fighting over Oil: Introducing A New Dataset," Conflict Management and Peace Science, 24(3), 239-256.

Lysenko, A. J., And N. I. Semashko (1968): "Geography of malaria. A medico-geographic profile of an ancient disease," Itogi Nauki: Medicinskaja Geografija, pp. 25-146.

McPeak, J., P. D. Little, and C. Doss (2012): Risk and Social Change in an African Rural Economy: Lifelihood in Pastoralist Communities. Routledge Press, London and New York.

Michalopoulos, S., and E. Papaioannou (2013a): "National Institutions and Subnational Development in Africa," Quarterly Journal of Economics, 129(1), 151-213.

(2013b): "Pre-Colonial Ethnic Institutions and Contemporary African Development," Econometrica, 81(1), 113-152.

New, M., D. Lister, M. Hulme, and I. Makin (2002): "A high-resolution data set of surface climate over global land areas," Climate Research, 21(1), 1-25.

Onwujekwe, O., R. Chima, and P. Okonkwo (2000): "Economic burden of malaria illness on households versus that of all other illness episodes: a study in five malaria holo-endemic Nigerian communities," Health Policy, 54, 143-159. 
Piel, F. B., A. P. Patil, R. E. Howes, O. A. Nyangiri, P. W. Gething, M. Dewi, W. H. Temperley, T. N. Williams, D. J. Weatherall, and S. I. Hay (2013): "Global epidemiology of sickle haemoglobin in newborns: a contemporary geostatistical model-based map," The Lancet, 381, 142-151.

Pinkovskiy, M. (2013): "Economic Discontinuities at Borders: Evidence from Satellite Data on Lights at Night," Mimeo MIT.

Pinkovskiy, M., and X. Sala-i Martin (2016): "Lights, Camera, Income! Illuminating the National Accounts-Household Surveys Debate," Quarterly Journal of Economics, 131(2), 579-631.

Ramankutty, N., J. A. Foley, J. Norman, and K. McSweeney (2002): "The global distribution of cultivable lands: current patterns and sensitivity to possible climate change," Global Ecology and Biogeography, 11(5), 377-392.

SACHS, J. D. (2003): "Institutions Don't Rule: Direct Effects of Geography on Per Capita Income," NBER Working Paper, 9490.

Sicuri, E., A. Vieta, L. Lindner, D. Constenla, and C. Sauboin (2013): "The economic costs of malaria in children in three sub-Saharan countries: Ghana, Tanzania and Kenya," Malaria Journal, 12(307), 1-14.

Stanisic, D. I., AND OThERs. (2015): "Acquisition of antibodies against Plasmodium falciparum merozoites and malaria immunity in young children and the influence of age, force of infection, and magnitude of response," Infection and Immunity, 83(2), 646-660.

Weidmann, N. B., J. K. RD, and L.-E. Cederman (2010): "Representing Ethnic Groups in Space: A New Dataset," Journal of Peace Research, 4(47), 491-499.

Weil, D. (2010): "Endemic Diseases and African Economic Growth: Challenges and Policy Responses," Journal of African Economies, 19(3), 81-109.

(2011): "Malaria and Early Economic Development in Africa," Mimeo, Brown University.

(2016): "Gyrations in African Mortality and their Effect on Economic Growth," Economic Journal, forthcoming. 
Table A1: Data Sources and Description of Main Variables of Interest

Variable Description and Data Sources

Dependent Variable: Log Night Lights per Capita. Log of (average) Night Density at Night divided by (average) Population in the cell respectively given by:

Light Density at Night. Average night light intensity in the cell. Source: constructed with data from NOOA National Geophysical Data Centre for the year 1995.

Population. Average population in the cell in year 1995. Source: constructed as the mean population across 2.5 arc-minutes grid. Data from he Center for International Earth Science Information Network - CIESIN - Columbia University, United Nations Food and Agriculture Programme - FAO, and Centro Internacional de Agricultura Tropical CIAT. 2005. Gridded Population of the World, Version 4 (GPWv3): Population Count Grid. Palisades, NY: NASA Socioeconomic Data and Applications Center (SEDAC). http://sedac.ciesin.columbia.edu/data/set/gpw-v3-population-count.

\section{Measures of Malaria Exposure and Genetic Immunities:}

Clinical Incidence of Malaria (Projected). Modeled clinical incidence of Plasmodium falciparum malaria (2000-2015), detrended for country-specific non-linear time trends. Measured as number of cases per 1000 people per year. Source: Bhatt et al. (2015), retrieved from http://www.map.ox.ac.uk/.

Malaria Ecology. Index measuring the force and stability of malaria transmission based on biological characteristics of diverse vector mosquitoes and their interaction with climate. Data source: Kiszewski, Mellinger, Spielman, Malaney, Sachs, and Sachs (2004).

High Malaria Risk Dummy. Based on the Malaria Ecology index, we constructed a dummy variable - Malaria Intermediate - which takes value one in cells with low to intermediate force and stability of transmission. This variables takes value 0 in cells where malaria cannot be transmitted, either because Anopheles vectors are not present or because climatic conditions for transmission are absent, and in cells with with very high Malaria Ecology (larger than 15). Data source: Kiszewski, Mellinger, Spielman, Malaney, Sachs, and Sachs (2004).

Malaria Endemicity in 1900. Average Historical Malaria Endemicity in the $1 \mathrm{x} 1$ degree grid cell. Source: average Historical Malaria Endemicity is constructed as the 1x1 degree cell average of the Malaria Endemicity level, devised by Lysenko and Semashko (1968) and digitalized by Hay et al. (2004)., computed using ArcGIS with data in EASE GLOBAL GRID projection.

Sickle Cell Trait Prevalence Percentage. Average predicted frequency of sickle haemoglobin alleles in the general population in the cell. Source: Piel et al. (2013). 
Table A2: Data Sources and Description of Covariates

\begin{tabular}{l}
\hline \hline Variable Description and Data Sources \\
\hline Average Temperature. Average annual cell temperature (baseline period 1961-1990). \\
Source: FAO/IIASA, 2011-2012. Global Agro-ecological Zones (GAEZ v3.0). FAO Rome, \\
Italy and IIASA, Laxenburg, Austria. \\
Average Precipitation. Average cell monthly precipitation mm/month (baseline period \\
1961-1990). Source: CRU CL 2.0 data from New, Lister, Hulme, and Makin (2002). \\
Mean Elevation. Average cell elevation. Source: National Oceanic and Atmospheric \\
Administration (NOAA) and U.S. National Geophysical Data Center, TerrainBase, release \\
1.0 (CD-ROM), Boulder, Colo. \\
Ruggedness. Average 1x1 degree cell ruggedness (Terrain Ruggedness Index, 100 m). \\
Source: mean ruggedness is constructed as the 1x1 degree cell average of elevation across \\
grids, computed using ArcGIS with data in EASE GLOBAL GRID projection, with data \\
from Terrain Ruggedness Index originally devised by Riley, DeGloria, and Elliot (1999), \\
obtained through http://diegopuga.org.
\end{tabular}

Cell Area. Natural logarithm of the cell area.

Total Water Area. Total area occupied by water in the cell (seas, oceans, lakes and rivers). Source: constructed with Digital Chart of the World inwater shapefile and the Digital Chart of the World oceans and sea shapefile.

Absolute Latitude. Absolute latitudinal distance of the centroid of the cell.

Ln Distance Coast. Natural logarithm of the average cell distance to closest coast. Source: constructed with coastline shapefile from Global Self-consistent Hierarchical Highresolution Geography Version 4.2.2 January 1, 2013.

Ln Distance Capital. Natural logarithm of the average cell distance to the country capital. Source: constructed with the World Capital shapefile.

Ln Distance Border. Natural logarithm of the cell distance to closest border. Source: constructed with coastline shapefile from Global Self-consistent Hierarchical High-resolution Geography Version 4.2.2 January 1, 2013.

Ln Distance River. Natural logarithm of the average cell distance to the closest river. Source: constructed using Major Rivers World Selected (p3w) shapefile (from www.naturalearth.com).

Ln Distance Adis Ababa. Natural logarithm of the geodesic distance to Adis Ababa.

Land Suitability. Average land suitability in the cell. Source: Ramankutty, Foley, Norman, and McSweeney (2002).

Diamond Mines. Indicator variable taking value 1 if at least one petrol field is located in the cell, 0 otherwise. Source: Gilmore et al. (2005)

Petrol Fields. Indicator variable taking value 1 if at least a diamond mine is located in the cell, 0 otherwise. Source: Lujala et al. (2007).

Number of Ethnic Groups, GREG. Number of languages in the 1x1 degree cell. Source: constructed with a (ArcGIS) spatial join between a 1x1 degree grid and the GREG shapefile from the digitized version of the Soviet Atlas Narodov Mira (available from Weidmann, Rod, and Cederman (2010)). We exclude all intersections that measures less than 10 squared $\mathrm{km}$ and all cells with an area smaller than 1000 squared $\mathrm{km}$. 